\title{
Outer Membrane Proteins as a Mechanism of Resistance in Multidrug-Resistant Klebsiella Clinical Isolates
}

\author{
Rasha M. EL-Morsi ${ }^{1 *}$, Alaa EL-Din M. Shwakey ${ }^{2}$ and Marwa M. Azab ${ }^{1}$ \\ ${ }^{1}$ Department of Microbiology and Immunology, Faculty of Pharmacy, \\ Suez Canal University, Egypt \\ ${ }^{2}$ Department of Microbiology and Immunology, Faculty of Pharmacy, Cairo University, Egypt \\ *Corresponding author
}

\section{A B S T R A C T}

\begin{tabular}{|c|}
\hline Keywords \\
\hline $\begin{array}{l}\text { Outer membrane } \\
\text { proteins, Multidrug- } \\
\text { resistant (MDR) } \\
\text { Klebsiella isolates, } \\
\text { Minimal inhibitory } \\
\text { concentrations } \\
\text { (MICs), PAGE. }\end{array}$ \\
\hline Article Info \\
\hline $\begin{array}{l}\text { Accepted: } \\
28 \text { August } 2017 \\
\text { Available Online: } \\
\text { 10 September } 2017\end{array}$ \\
\hline
\end{tabular}

This study was designed to investigate the role of the outer membrane proteins as a mechanism of resistance in Klebsiella isolates collected from Tanta university Hospital in Tanta, Egypt and to correlate between the Outer membrane proteins (OMPs) profiles and the resistance patterns of the tested isolates. The outer membrane of gram-negative bacteria plays a significant role in a variety of functions and is composed of a bilayer containing phospholipids, lipopolysaccharide and outer membrane proteins (OMPs). Two major non-specific porins, namely Omp K35 and Omp K36 have been described in Klebsiella pneumoniae. A total of 13 multidrug-resistant (MDR) Klebsiella isolates were obtained. Antibiotic susceptibility test was performed by disk diffusion method. Minimal inhibitory concentrations (MICs) were determined by broth microdilution method for the selected antibiotics. Analysis of the outer membrane profile was performed on $12 \%$ separating acrylamide gel and vertical polyacrylamide gel electrophoresis (PAGE) apparatus. It was found that The relation between the resistance patterns and OMPs profiles of the tested isolates was difficult to be determined as strains having the same resistance pattern may exhibit different OMPs profiles and vice versa

\section{Introduction}

The outer membrane of gram-negative bacteria plays a significant role in a variety of functions and is composed of a bilayer containing phospholipids lipopolysaccharide and outer membrane proteins OMPs). One family of OMPs the porins, are present in large amounts in the outer membrane and form water filled channels that permit the diffusion of small hydrophilic solutes across the membrane [1].

Two major non-specific porins, namely Omp K35 and Omp K36 have been described in K.pneumoniae. Omp K35 and Omp K36, porins were found to be the homologues of porins OmpF and OmpC from E.coli respectively. OmpK36 porins allow the diffusion of a wide variety of molecules, including bacterial nutrients and antimicrobials [2, 3].

Alterations in the composition and structure of outer membrane alter antibiotic permeation leading to drug resistance. Numerous outer membrane changes have been correlated with antibiotic resistance including porindeficiency and lipopolysaccharide (LPS) structural changes [4]. In some instances at 
least, it has been argued that the outer membrane barrier alone is not sufficient to provide substantial resistance to antimicrobial agents [4]. Loss of porins in $K$. pneumoniae strains producing extended-spectrum $\beta$ lactamases (ES $\beta$ Ls) has been shown to cause resistance to cefoxitin, increased resistance to third-generation cephalosporins and monobactams, and decreased susceptibility to fluoroquinolones [5].

\section{Materials and Methods}

Isolation and identification of clinical isolates

A total of 13 MDR (multidrug-resistant) Klebsiella isolates were obtained from patients in different departments including Neonatology, oncology and ICU (intensive care units) admitted to Tanta University Hospital, Tanta, Egypt.

Clinical specimens including urine, blood and tracheal aspirates were examined and identified by standard microbiological procedures and biochemical reactions $[6,7]$.

\section{Reference Strains}

Escherichia coli strain ATCC $\AA \quad 25922^{\mathrm{TM}}$ (American Type culture collection, USA) was given by NAMRU -3 in Cairo to the Microbiology Diagnostic and Infection Control Unit (MDICU) in the department of Medical Microbiology and Immunology, Faculty of Medicine, Mansoura University.

\section{Antimicrobial susceptibility testing}

Susceptibilities of the isolates were tested against 23 antimicrobials of different classes using the Kirby-Bauer method as recommended on Mueller-Hinton agar with commercially available antimicrobial disks (Oxoid, UK), according to Clinical Laboratory Standards Institute [8, 9].

\section{Determination of minimum inhibitory} concentrations

Minimum inhibitory concentrations of 23 imipenem resistant isolates were determined by broth microdilution method against 6 antimicrobial agents. Pure forms of 11 antibiotics were used (Manfacturers: E.I.P.I.CO, CID and Pharco B International, Egypt).

The scheme for preparing dilutions of antimicrobial agents and the methodology was according to CLSI guidelines [9].

ESBL detection by Double Disc Diffusion Synergy Test (DDST)

Isolates with resistance to any of the $3 \mathrm{GC}$ (Third generation cephalosporins) were subjected to the standard DDST [10]. Disks containing $(30 \mu \mathrm{g})$ of aztreonam, ceftazidim, cefepime, ceftriaxone and cefotaxime were placed around a disk of AMC (20 $\mu \mathrm{g}$ of amoxicillin plus $10 \mu \mathrm{g}$ of clavulanate) in a distance of $30 \mathrm{~mm}$ center to center.

\section{Analysis of OMPs}

The outer membrane proteins (OMPs) of all the recovered Klebsiella isolates were prepared and the protein contents were analyzed as described by El-Banna et al., [11].

The OMPs were obtained after treatment of cell membranes recovered by ultracentrifugation using High intensity ultrasonic processor (Cole Parmer, USA) with Sodium dodecyl sulphate (SDS) (Sigma, USA). Analysis of the outer membrane profile was performed on $12 \%$ separating acrylamide gel and one dimensional SDSpolyacrylamide gel electrophoresis (SDSPAGE). Gels were visualized by staining with Coomassie Brilliant Blue R-250 (CBBR-250) (Sigma, USA). 


\section{Results and Discussion}

A total of 13 MDR Klebsiella isolates (4 urine, 5 blood, 1 ETT and 1 wound, 2 unknown) were obtained from different department of Tanta University Hospital. Out of them only 2 isolates (15\%) were Klebsiella oxytoca and the rest 11 isolates (85\%) were Klebsiella pneumoniae. The antimicrobial resistance patterens and MIC of the examined isolates were illustrated in tables 1 and 2 .

All of 13 Klebsiella isolates were (multidrugresistance) MDR, all (100\%) of the isolates were resistant to Ampicillin, Amoxicillin, Cephradine, Cefaclor, Cefotaxime and Cefoperazon and all of them were sensitive to Imipenem. The phenotypic screening of ESßLs by double disc diffusion synergy test showed that $13(100 \%)$ of the obtained Klebsiella isolates were ESBLs producers.

The outer membrane proteins (OMPs) of the 13 Klebsiella isolates were prepared. Polyacrylamide gel electrophoresis of the protein contents was performed. Representative photos are shown in figures 1 and 2. Visual examination of the electropherograms revealed that different protein bands at molecular weights of 66 to $14 \mathrm{KDa}$ can be detected, overproduced or lost in the different electropherograms obtained. Proteins with molecular weights of $45 \mathrm{KDa}$ and $36 \mathrm{KDa}$ represent major proteins as they were detected in almost all the tested isolates.

The relation between the resistance patterns and OMPs profiles of the tested isolates was difficult to be determined as strains having the same resistance pattern may exhibit different OMPs profiles and vice versa. The presence, absence or overproduction of each of the major proteins differs among the isolate as shown in table 3.

All of our isolates were MDR isolates and all of them produce ESßLs. This is in accordance with what was reported by Lopes et al., [12] that Klebsiella pneumoniae isolates were resistant to many antibiotics mainly third generation cephalosporins and pencillins due to acquisition of plasmids that harbor genes codes for the production of extendedspectrum $\beta$-lactamases.

Fig.1 SDS-Polyacrylamide gel of the outer membrane proteins of selected ES $\beta$ Ls producing Klebsiellaisolates, lane 1: protein molecular weight marker; lane2:K22; lane3:K11; lane 4:K16; lane 5: K5; lane 6: K3; lane 7:K23; lane 8; K52 lane 9: K55

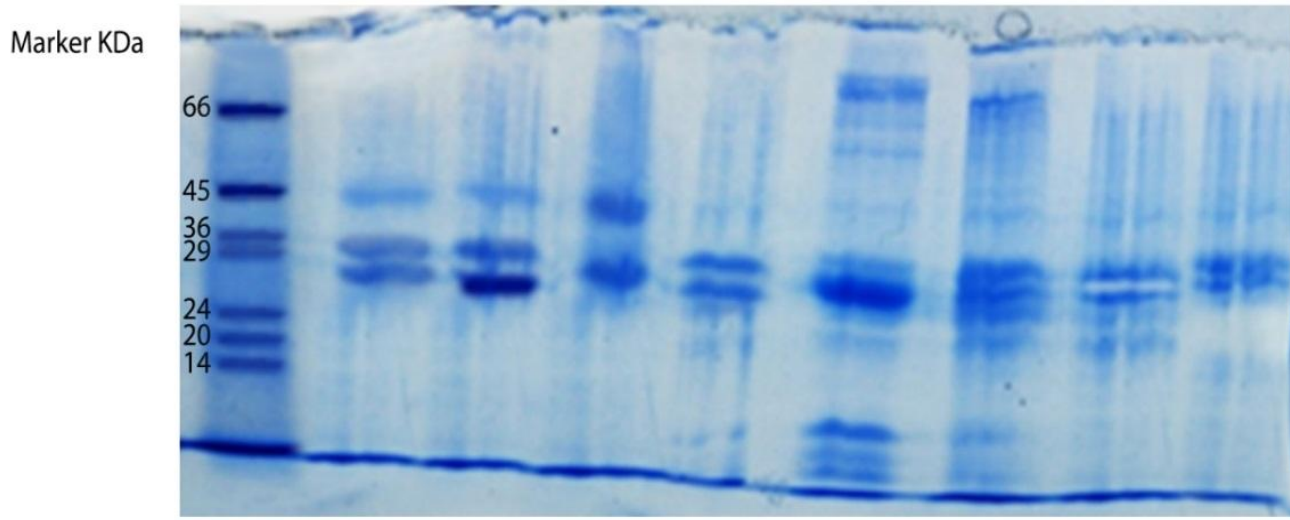


Fig.2 SDS-Polyacrylamide gel of the outer membrane proteins of selected ES $\beta$ Ls producing Klebsiella isolates, lane 1: protein molecular weight marker; lane2:K67; lane3:K34; lane 4:K401; lane 5: K202; lane 6: K36

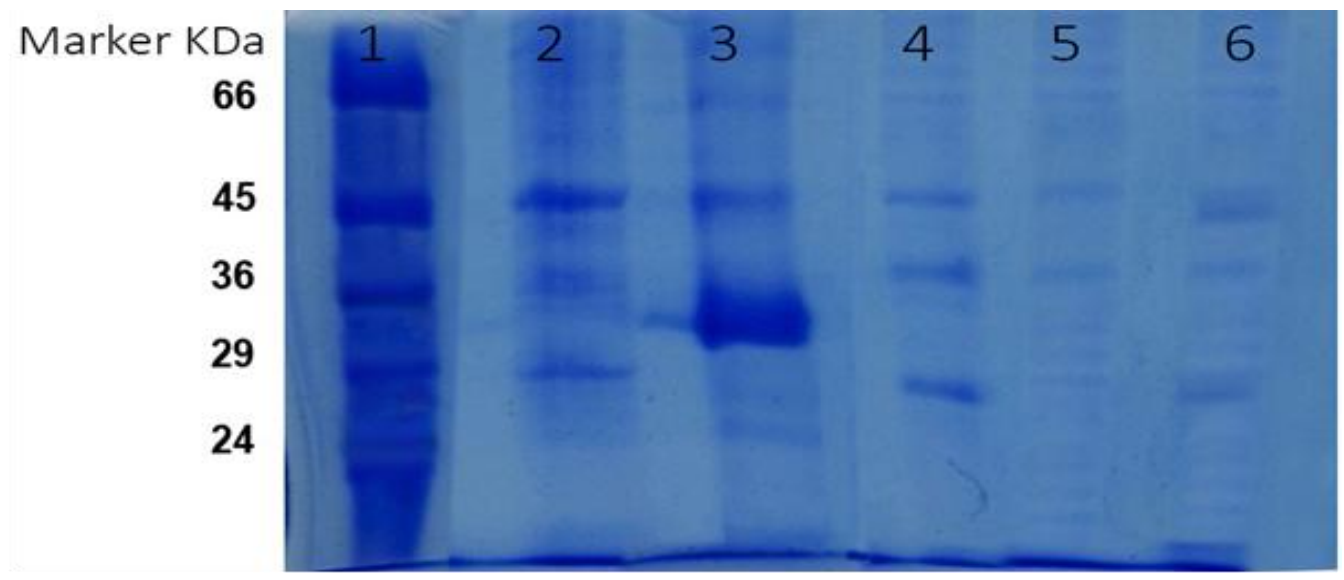

Table.1 The site and Resistance pattern patterns of the examined Klebsiella isolates

\begin{tabular}{|c|c|c|}
\hline \multirow{2}{*}{ Isolate code } & Site & \multirow{2}{*}{ Resistance pattern } \\
\hline & Department & \\
\hline K22 & Urine-Oncology & $\begin{array}{l}\text { AM,AMOX, AMC,PRL, CE,CEC, CTX,CFP, CAZ, FEP,NA,OFX, } \\
\text { CIP,LEV, TE, C, SXT,S,E, GN,TOB, AK. }\end{array}$ \\
\hline K11 & Blood-Neonatology & $\begin{array}{l}\text { AM,AMOX,PRL, CE,CEC, CTX, CAZ,CFP,FEP,NA,OFX CIP,LEV, } \\
\text { TE, E,TOB, GN }\end{array}$ \\
\hline K16 & Urine-Oncology & $\begin{array}{l}\text { AM,AMX,PRL, CE,CEC, CTX, CAZ, CFP,NA,OFX, CIP,LEV, C, E, } \\
\text { SXT,S, TE,TOB, GN. }\end{array}$ \\
\hline K5 & ND & $\begin{array}{c}\text { AM,AMOX,PRL, CE,CEC, CTX, CAZ,CFP,FEP,NA,OFX, CIP,LEV, } \\
\text { C, E, SXT,S, TE,TOB, GN. }\end{array}$ \\
\hline K3 & Urine-Oncology & $\begin{array}{c}\text { AM, AMX,PRL, CE,CEC, CTX, } \\
\text { CAZ,CFP,C,E,SXT,S,TE,TOB,NA,OFX,CIP,LEV. }\end{array}$ \\
\hline K23 & ETT-ICU & $\begin{array}{l}\text { AM,AMOX,PRL, CE,CEC, CTX,CAZ, CFP,NA,OFX,CIP,LEV, C, TE, } \\
\text { TOB, GN. }\end{array}$ \\
\hline K52 & Blood-Neonatology & $\begin{array}{l}\text { AM,AMOX,PRL, CE,CEC, CTX, CAZ,CFP,NA,OFX, CIP,LEV, } \\
\text { E,SXT, TE, GN,S. }\end{array}$ \\
\hline K55 & Urine-Oncology & $\begin{array}{l}\text { AM, AMOX,AMC,PRL, CE,CEC,CFP, CTX, CAZ, } \\
\text { FEP,NA,OFX,CIP,LEV, TE, C, SXT,S, E, GN. }\end{array}$ \\
\hline KAE & Blood-Neonatology & $\begin{array}{l}\text { AM,AMOX,AMC,PRL, CE,CEC, CTX, CAZ,CFP,FEP,NA,OFX, } \\
\text { CIP,C, E, SXT,TE, GN,TOB, AK }\end{array}$ \\
\hline K34 & Wound infection & $\begin{array}{l}\text { AM,AMOX,PRL, CE,CEC,CTX,CFP,NA,OFX, CIP,LEV, C, E, SXT, } \\
\text { S,GN. }\end{array}$ \\
\hline K401 & Blood-Neonatology & AM,AMOX,PRL, CE,CEC, CTX,CFP,TE, C, E,S,TOB, GN \\
\hline K202 & Blood-Neonatology & $\begin{array}{l}\text { AM, AMOX,AMC,PRL, CE,CEC, CTX, CAZ,CFP, FEP,C, TE, } \\
\text { E,GN,TOB. }\end{array}$ \\
\hline K36 & ND & $\begin{array}{l}\text { AM,AMOX, PRL, CE,CEC, CTX,CFP, NA,OFX, CIP,LEV,C, TE, } \\
\text { SXT, E,GN,TOB. }\end{array}$ \\
\hline
\end{tabular}

Note:AM:Ampicillin,AMX:Amoxicillin, AMC: Amoxicillin-Clavulante, PRL: Piperacillin, CE: Cephradine, CEC:

Cefaclor, CTX: Cefotaxime,CAZ: Ceftazidime, CFP: Cefoperazon FEP:Cefepime, IMP: Imipenem, AK: Amikacin, GN:Gentamycin, S:Streptomycin, TOB:Tobramycin, NA:Nalidixic acid, CIP:Ciprofloxacin OFX:Ofloxacin, LEV: levofloxacin, SXT:Cotrimoxazol, TE:Tetracyclin, E: Erythromycin, C: Chloramphenicol.

NK: Not Known

ETT-ICU: Endotracheal Tube - Intensive Care Unit. 
Table.2 The MIC values of the examined Klebsiella isolates

\begin{tabular}{|l|l|l|l|l|l|l|l|l|l|l|c|}
\hline Code & Levo & Moxi & Gemi & Gati & CIP & GN & AK & CFP & CAZ & CTX & FEP \\
\hline K22 & 32 & 64 & 256 & 64 & 512 & $>1024$ & $>1024$ & $>1024$ & 256 & $>1024$ & 256 \\
\hline K11 & 32 & 128 & 128 & 128 & 32 & 64 & - & 512 & 256 & 512 & $>1024$ \\
\hline K16 & 64 & 128 & 128 & 128 & 128 & 128 & - & 128 & 64 & 256 & - \\
\hline K5 & 16 & 64 & 32 & 32 & 128 & $>1024$ & - & $>1024$ & 128 & 1024 & $>1024$ \\
\hline K3 & 16 & 64 & 32 & 32 & 256 & - & - & $>1024$ & 256 & $>1024$ & - \\
\hline K23 & 32 & 128 & 16 & 8 & 64 & 512 & - & $>1024$ & 256 & $>1024$ & - \\
\hline K52 & 16 & 128 & 64 & 32 & 128 & 256 & - & 512 & 64 & 256 & - \\
\hline K55 & 128 & 128 & 128 & 128 & $>1024$ & $>1024$ & - & 1024 & 256 & $>1024$ & $>1024$ \\
\hline KAE & - & 16 & 8 & 64 & 128 & $>1024$ & 128 & $>1024$ & 1024 & $>1024$ & 1024 \\
\hline K401 & 32 & 128 & 128 & 128 & - & $>1024$ & - & 1024 & - & 128 & - \\
\hline K202 & - & 256 & 8 & - & 16 & $>1024$ & - & $>1024$ & 1024 & $>1024$ & 128 \\
\hline K36 & 16 & 256 & 64 & 16 & 64 & 256 & - & 1024 & - & 128 & - \\
\hline
\end{tabular}

Note: Levo: Levofloxacin, Moxi: moxifloxacin, Gemi: gemifloxacin, Gati: gatifloxacin, CIP: Ciprofloxacin, GN:

Gentamycin, AK: Amikacin, CFP: Cefoperazon, CAZ: Ceftazidime, CTX: Cefotaxime, FEP: Cefepime.

Table.3 The outer membrane protein patterns in the examined Klebsiella isolates

\begin{tabular}{|l|c|c|c|c|c|c|c|c|}
\hline \multirow{2}{*}{ Isolate code } & \multicolumn{7}{|c|}{ OMPs changes } & \multirow{2}{*}{ Pattern code } \\
\cline { 2 - 8 } & 66 & 45 & 36 & 29 & 24 & 20 & $\mathbf{1 4}$ & I \\
\hline K22 & - & + & + & + & - & - & - & II \\
\hline K11 & - & + & + & ++ & - & - & - & III \\
\hline K16 & - & ++ & - & ++ & - & - & - & IV \\
\hline K5 & - & - & + & + & - & - & - & V \\
\hline K3 & + & - & + & ++ & - & - & + & VI \\
\hline K23 & + & - & + & + & - & - & + & IV \\
\hline K52 & - & - & + & + & - & - & - & IV \\
\hline K55 & - & - & + & + & - & - & - & I \\
\hline K67 & - & + & + & + & - & - & - & VII \\
\hline K34 & + & + & - & ++ & - & - & - & I \\
\hline K401 & - & + & + & + & - & - & - & VIII \\
\hline K202 & - & - & - & - & - & - & - & VI \\
\hline K36 & - & - & - & - & - & - & - & \\
\hline
\end{tabular}

-absent, + present, ++overproduced

Gram negative bacterial outer membranes are poorly permeable to both hydrophobic and hydrophilic molecules. So, most antimicrobial agents other than $\beta$-lactam must cross the membrane in order to reach their intracellular drug targets and so require the presence of porin to bypass the asymmetric bilayer of phospholipid and lipopolysaccharide membrane [13]. Consequently, loss of porins ompK 35 and ompK 36 led to an increase in carbapenem, ciprofloxacin, and chloramphenicol resistance [14].

Porins are outer membrane proteins (OMPs) that allow the nonspecific diffusion of small molecules into the bacterial cell. Most of the 
studies about OMPs have been carried out with Escherichia coli, in which two major porins (OmpC and OmpF) have been characterized. Loss of either of them has been related to antibiotic resistance [15]. Decreased permeability can produce significant levels of resistance that may be increased when it is combined with enzymatic inactivation [15]. In $K$. pneumoniae, two main porins have been characterized: OmpK35 (the homolog of OmpF) and OmpK36 (the homolog of OmpC) $[3,16]$.

Recently, loss of the OmpK36 porin has been associated with both cefoxitin resistance and increases in cephalosporin and quinolone MICs [5].

In our study the OMPs of the ES $\beta$ Lsproducing Klebsiella isolates were studied. The electrophoretic profile of the selected isolates showed the presence of different protein bands in the electropherograms of the tested isolates. These bands have molecular weights from 66 to $14 \mathrm{KDa}$. Proteins with molecular weights of 36 and $29 \mathrm{KDa}$ represent major proteins as they were detected in almost all the tested isolates.

In our work we cannot correlate between the OMPs profiles and the resistance patterns of the tested isolates as isolates which had more protein bands not differ greatly in resistance pattern from other isolates which had less or no protein bands.

This finding is similar to other reports $[5,17]$ which reported that the specific contribution of alterations in porin expression and the resistance patterns were difficult to determine, because other mechanisms of resistance are commonly present in porin-deficient strains (such as production of $\beta$-lactamases or aminoglycoside-modifying enzymes, modified topoisomerases or energy-dependent efflux systems).

\section{Conflict of Interest}

The authors confirm that this article content has no conflicts of interest.

\section{References}

1. Domenech-Sanchez A, Hernandez-Alles S, Martinez-Martinez L, Benedi JC, Arberti S. Identification and Characterization of a New Porin Gene of Klebsiella pneumoniae: In Role in $\beta$ Lactam Antibiotics Resistance". J. Bacteriol 1991; 81:2726-32.

2. Yigit H, Anderson JG, Biddle JW, Steward CD, Rasheed JK, Valera LL, McGowen JE, Tenovar FC. Carbapenem resistance in a clinical isolate of Enterobacter aerogenes is associated with decreased expression of $\mathrm{OmpF}$ and $\mathrm{OmpC}$ porin analogs. Antimicrob Agents Chemother 2002; 46: 3817-22.

3. Alberti SF, Rodriguez-Zuinones F, Schirmer T, Rummel G, Thomas JM, Rosenbusch JP, Benedi VJ. A porin from Klebsiella pneumoniae: sequence homology, three dimensional structures and complement binding. Infect Immun 1995; 63:903-10.

4. Nikaido H. Prevention of drug access to bacterial targets: permeability barriers and active efflux. Science 1994; 264:382-88.

5. Marti'nez-Marti'nez L, Hernandez-Alles S, Albertis S, Tomas JM, Benedi VJ, Jacoby GA. In vivo selection of porindeficient mutants of Klebsiella pneumoniae with increased resistance to cefoxitin and expanded-spectrum cephalosporins. Antimicrob Agents Chemother 1996; 40:342-48.

6. Collee JG, Miles RS. Tests of identification of bacteria". In: Mackie and MacCarthery Practical Medical Microbiology, 40 ${ }^{\text {th }}$ ed, J.G .Collee, A.G. Fraser, B.P.Marmion, and A. Simmons, (eds), Churchil Livingstone; P.141, 1996.

7. Cheesbrough M. Collection, transport and examination of specimens, Cited In: Medical Laboratory Manual for Tropical Countries, 4th ed., Cheesbrough, M., 
Butter Worth- Heinemann, Oxoford; PP:100-195, 1993.

8. Bauer A, Kirby W, Sherris, JC, Turck M. Antibiotic susceptibility testing by standardized single disk method. Am J Clin Pathol 1996; 45: 493-6.

9. Clinical and Laboratory Standards Insitute CLSI. Performance Standards for Antimicrobial Susceptibility Testing. Clinical and Laboratory Standard Institute. Wayne, Pennsylvannia, USA 22th informational supplement. CLSI document M100-S22.Vol.32, No.1. 2012.

10.

panu T, Luzzaro F, Perilli M, Amicosante G, Toniolo A, Fadda G, The Italian ESBL Study Group. Occurrence of extendedspectrum $\beta$-lactamases in members of the family Enterobacteriaceae in Italy: implications for resistance to B-lactams and other antimicrobial drugs. Antimicrob. Agents Chemother 2002; 46:196-202.

11. El-Banna T, El-Mahdy NA, Abo-Skeena M. Plasmids coding for colonization factor antigen/I, heat-stable enterotoxin STa and heat-labile enterotoxin LT-1 in enterotoxigenic Escherichia coli O78:H12 isolates in Egypt. AZ. J. Microbiol 1998;40: 99-117.

12. 12 Lopes ACS, Rodrigues JF, Junior MAM. Molecular Typing of Klebsiella pneumoniae isolates from public hospitals in Recife, Brazil. Microbiol. Res 2005; 160: 37-45.

13. Nikaido H. Molecular basis of bacterial outer membrane permeability revisited. Microbiol Mol Biol Rev 2003;67 :593656.

14. Kaczmarek FM, Dib-Hajj F, Shang W, Gootz TD. High-Level Carbapenem Resistance in a Klebsiella pneumoniae Clinical Isolate Is Due to the Combination of bla(ACT-1) $\beta$-Lactamase Production, Porin OmpK35/36 Insertional Inactivation, and Down Regulation of the Phosphate Transport Porin PhoE. Antimicrob. Agents Chemother 2006; 50, 3396-3406.

15. Nikaido H. Outer membrane barrier as a mechanism of antimicrobial resistance. Antimicrob. Agents Chemother 1989; 33: 1831-36.

16. Hernández-Allés S, Albertí S, Rubires X, Merino S, Tomás JM, Benedí VJ. Isolation of $\mathrm{Fe} 3-11$, a bacteriophage specific for the Klebsiella pneumoniae porin OmpK36, and its use for the isolation of porin-deficient mutants. Can J Microbiol 1995; 41:399-406.

17. Wasfi R, Elkhatib WF, Ashour HM. Molecular typing and virulence analysis of multidrug resistant Klebsiella pneumoniae clinical isolates recovered from Egyptian hospitals. Scientific RepoRts 2016; 6:38929.

\section{How to cite this article:}

Rasha M. EL-Morsi, Alaa EL-Din M. Shwakey and Marwa M. Azab. 2017. Outer Membrane Proteins as a Mechanism of Resistance in Multidrug-Resistant Klebsiella Clinical Isolates. Int.J.Curr.Microbiol.App.Sci. 6(9): 3037-3043. doi: https://doi.org/10.20546/ijcmas.2017.609.373 